\title{
Time course analysis of enzyme-catalyzed DNA polymerization
}

\section{DOI:}

10.1021/acs.biochem.6b00442

\section{Document Version}

Accepted author manuscript

Link to publication record in Manchester Research Explorer

\section{Citation for published version (APA):}

Rentergent, J., Driscoll, M., \& Hay, S. (2016). Time course analysis of enzyme-catalyzed DNA polymerization. Biochemistry, 55(39), 5622-5634. https://doi.org/10.1021/acs.biochem.6b00442

\section{Published in:}

Biochemistry

\section{Citing this paper}

Please note that where the full-text provided on Manchester Research Explorer is the Author Accepted Manuscript or Proof version this may differ from the final Published version. If citing, it is advised that you check and use the publisher's definitive version.

\section{General rights}

Copyright and moral rights for the publications made accessible in the Research Explorer are retained by the authors and/or other copyright owners and it is a condition of accessing publications that users recognise and abide by the legal requirements associated with these rights.

\section{Takedown policy}

If you believe that this document breaches copyright please refer to the University of Manchester's Takedown Procedures [http://man.ac.uk/04Y6Bo] or contact uml.scholarlycommunications@manchester.ac.uk providing relevant details, so we can investigate your claim.

\section{OPEN ACCESS}




\title{
Time course analysis of enzyme-catalyzed DNA polymerization
}

\author{
Julius Rentergent, Max D. Driscoll, and Sam Hay* \\ Manchester Institute of Biotechnology, University of Manchester, UK \\ E-mail: sam.hay@manchester.ac.uk
}

Phone: +44(0)1613065141

\section{Running header}




\begin{abstract}
Extracting kinetic parameters from DNA polymerase-catalysed processive polymerisation data using traditional initial-rate analysis has proven problematic for multiple reasons: The first substrate, DNA template, is a heterogeneous polymer and binds tightly to DNA polymerase. Further, the affinity and speed of incorporation of the second substrate, deoxynucleoside triphosphate (dNTP), varies greatly depending on the nature of the templating base and surrounding sequence. Here, we present a mathematical model consisting of the DNA template-binding step and a MichaelisMenten-type nucleotide incorporation step acting on a DNA template with finite length. The model was numerically integrated and globally fitted to experimental reaction time courses. The time courses were determined by monitoring the processive synthesis of oligonucleotides of lengths between 50 and 120 nucleotides by DNA polymerase I (Klenow fragment exo $^{-}$) using the fluorophore PicoGreen. For processive polymerisation, we were able to estimate an enzyme-template association rate $k_{1}$ of $7.4 \mathrm{\mu M}^{-1} \mathrm{~s}^{-1}$, a disassociation rate $k_{-1}$ of $0.07 \mathrm{~s}^{-1}$, a $K_{\mathrm{d}}$ of $10 \mathrm{nM}$, and the steady-state parameters for correct dNTP incorporation give $k_{\text {cat }}$ of 2.5 to $3.3 \mathrm{~s}^{-1}$ and $K_{\mathrm{m}}$ of 0.51 to $0.86 \mu \mathrm{M}$. From the analysis of time courses measured at temperatures between 5 and $25^{\circ} \mathrm{C}$, an activation energy for $k_{\text {cat }}$ of $82 \mathrm{~kJ} \mathrm{~mol}^{-1}$ was calculated and it was found that up to $73 \%$ of Klenow fragment becomes inactivated or involved in unproductive binding at lower temperatures. Finally, a solvent deuterium kinetic isotope effect (KIE) of 3.0 to 3.2 was observed under processive synthesis conditions, which suggests that either the intrinsic KIE is unusually high, at least 30 to 40, or that previous findings, showing that the phosphoryl transfer step occurs rapidly and is flanked by two slow conformational changes, need to be re-evaluated. We suggest that the numerical integration of rate equations provides a high level of flexibility and generally produces superior results compared to initial-rate analysis in the study of DNA polymerase kinetics and, by extension, of other complex enzyme systems.
\end{abstract}


The enzyme DNA polymerase is of fundamental importance to the process of DNA replication, which is at the heart of life. The catalysed reaction is a phosphoryl transfer, in which a phosphodiester bond is formed between the 3' hydroxyl group of the primer and the $\alpha$-phosphate of the 5 ' end of an incoming dNTP (1). DNA polymerase I is a single polypeptide with 928 amino acid residues from Escherichia coli. Its large C-terminal fragment (Klenow fragment, KF) contains the (324-517aa) polymerisation domain and the (521-928aa) 3'-5' exonuclease domain, but not the (1-324aa) 5'-3' exonuclease domain (2). The remaining 3'-5' exonuclease activity is abolished in the D355A/E357A mutant (3), which retains the same structure and kinetic properties as the native protein (4). This simplifies KF to a suitable model enzyme for processive DNA polymerisation without the need to include depolymerisation steps.

A plethora of complexities can be ascribed to the kinetic mechanism of DNA polymerase. Many of these arise from the nature of its first substrate, DNA template. The DNA template is a heterogeneous polymer chain composed of four different types of dNTPs. Due to its length, it offers multiple DNA polymerase binding sites with varying properties, which may further change dynamically dependent on the degree of DNA polymerisation. DNA template also binds tightly to most DNA polymerases, which makes the application of steadystate kinetics difficult (see Discussion). Most DNA polymerases catalyse multiple dNTP incorporations before dissociating, and kinetic models need to account for this processivity. Lastly, the identity of the templating base guides the selection of the second substrate, dNTP. The correct dNTP must be chosen with a very high selectivity over all alternative substrates and the identity of the next correct dNTP may change after each incorporation.

There has been early interest in the construction of template-directed polymerisation models. When the role of DNA template-primer as initiator for synthesis was still unknown, Simha et al. (5) modelled the dNTP monomer adsorption as a first-order process on an 
infinite chain, and contrasted kinetic predictions made based on whether the availability of DNA polymerase restricts the number of active growing centers or not. Pipkin and Gibbs (6) extended the second case, in which polymerisation kinetics are assumed to be independent of DNA polymerase concentration, to the treatment of a template with finite length. In another report ( 7$)$, the polymer species were explicitly modelled by setting up a system of differential equations and these were solved with a Laplace transform. However, this was only possible when enzyme binding was assumed to be slow and irreversible up to the template end, where the rate of release was fast. All three reports show that the molecular weight distribution of DNA polymer species can be approximated by a Poisson distribution in their models (5-7). While such a statistical distribution serves as an excellent way to model the reaction progress in simple conditions, more complex models do not have a similar analytic solution. Most importantly, reactant concentrations need to be approximated to be constant and simplifying assumptions, such as permanent binding of polymerase to DNA template, are required and appropriate experimental conditions need to be enforced when collecting experimental data. Further, any non-uniform behaviour along the DNA template, such as the slow replication at a pausing site, cannot be readily integrated. The application of the statistical template-polymer approach has therefore been limited.

A more traditional approach was taken by McClure and Jovin (8) who developed an early detailed processive kinetic model for DNA polymerase I and used steady-state equations to determine kinetic parameters. They were the first to report a burst phase, ie a faster incorporation of the first nucleotide than the succeeding ones, and later extensions of the model enabled the investigation of polymerase translocation and processivity $(9)$. However, the initial-rate approach does not take finite template length into account and often fails when applied to high-affinity interactions such as the one between DNA polymerase and template. 
Most of the mechanistic details and thermodynamic parameters of dNTP incorporation have been determined by combining steady-state and pre-steady-state methods, first for DNA polymerase I (10) and later for KF (11-13). However, the pre-steady-state approach is usually carried out under single-turnover conditions. Although this simplifies the product analysis, the approach neglects post-chemistry reaction steps, translocation of the polymerase to the next template position and processive polymerisation (14).

Here, we present a highly flexible mathematical model for processive DNA polymerisation that explicitly contains the enzyme-template interactions and a finite DNA template length. Numerical integration of this model enables us to extract more information from experimental time course data than would have been possible with an initial-rate approach. The data were collected using our previously published PicoGreen (PG) assay (15).

\section{Model construction}

KF-catalysed DNA polymerisation is a complex process involving two substrates, DNA template and dNTP, in an ordered-binding mechanism, which is identical for all polymerase families (10). The KF mechanism is illustrated in Scheme 1 (see (16) for a review). First, KF binds to DNA to form a binary complex (the corresponding rate is given by $k_{1}$ ). Subsequently, dNTP binds to the KF-DNA complex $\left(k_{2}\right)$ and induces a conformational change $\left(k_{3}\right)(17)$. This is followed by catalysis of the phosphoryl transfer $\left(k_{4}\right)$ and a second conformational change $\left(k_{5}\right)(13)$. After release of the product pyrophosphate $\left(\mathrm{PP}_{\mathrm{i}}\right)$, the binary KF-DNA complex is restored and may either dissociate or undergo the next round of polymerisation.

A two-step model is presented in the form of a system of ordinary differential equations (ODEs), which has three main features: (i) the enzyme-template interaction is explicitly modelled, (ii) all remaining steps (bracketed part of Scheme 1) are condensed into one 
reaction following Michaelis-Menten kinetics, (iii) the polymer nature of DNA template is accounted for by including $2 n+2$ DNA species, where $n$ is the number of nucleotides on the ssDNA portion.

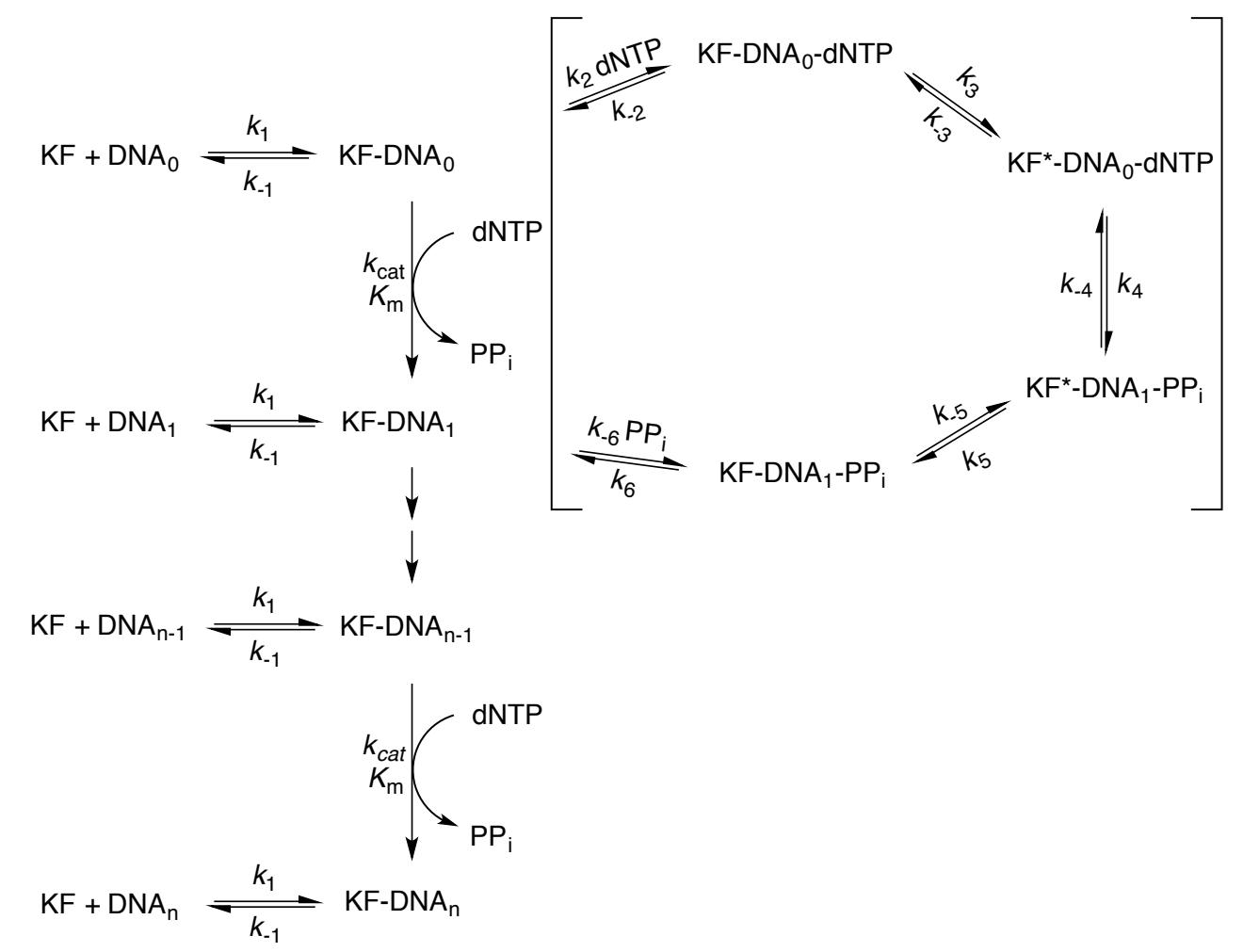

Scheme 1. Kinetic model for processive DNA polymerisation on a DNA template with finite template length $n$. $\mathrm{DNA}_{0}$ designates the inital template-primer species, while the fully polymerised template species is $\mathrm{DNA}_{\mathrm{n}}$. The binding of $\mathrm{KF}$ to DNA template is described by mass-action parameters $k_{1}$ and $k_{-1}$. Binding and disassociation can occur at any point, independent of the degree of polymerisation of the DNA template. The dNTP incorporation process is condensed to one step modelled by steady-state parameters $k_{\text {cat }}$ and $K_{\mathrm{m}}$, which consumes the substrate $\mathrm{dNTP}$ and releases pyrophosphate $\mathrm{PP}_{\mathrm{i}}$. The reverse reaction is assumed to be negligible. While the bracketed part is not included in the mathematical model, it illustrates the steps contributing to the steady-state parameters $k_{\text {cat }}$ and $K_{\mathrm{m}}$ based on the model by Dahlberg and Benkovic (13). The steps show dNTP binding $\left(k_{2}\right)$, pre-chemistry conformational change $\left(k_{3}\right)$, phosphoryl transfer $\left(k_{4}\right)$, post-chemistry conformational change $\left(k_{5}\right)$ and release of $\mathrm{PP}_{\mathrm{i}}\left(k_{6}\right)$.

The integration of template-binding dynamics is necessary, because dissociation from template $\left(k_{-1}\right)$ is the slowest step in the overall reaction scheme (11). Taking this into account, explicit modelling of the binding reaction enables the analysis of the remaining 
reaction scheme comprising the dNTP incorporation using Michaelis-Menten kinetics involving just two parameters, $k_{\text {cat }}$ and $K_{\mathrm{m}}$. In contrast, when applying the Michaelis-Menten equation to processive polymerisation data directly, the resulting parameters $k_{\text {cat }}$ and $K_{\mathrm{m}}$ are strongly dependent on the particular DNA template and experimental conditions chosen, and give little information on the DNA polymerisation process. For example, under singlenucleotide-incorporation conditions, in which just a single nucleotide is to be incorporated per template strand, the reported $k_{\text {cat }}$ would be equal to the dissociation rate $\left(k_{-1}\right)(11)$. Such analyses have therefore been criticised (18). Even the extension of the MichaelisMenten equation to a two-substrate model is not adequate when combined with an initialrate approach for reasons outlined in the Discussion. The solution presented here therefore does not rely on the estimation of initial rates, but instead focuses on the analysis of full reaction time courses.

Even though no initial-rate approach is used here, the Michaelis-Menten equation is still useful to construct a model with identifiable parameters. In Equation 1, $v$ is the dNTP incorporation velocity, which depends on the steady-state parameters $k_{\text {cat }}$ and $K_{\mathrm{m}}$, the concentration of the KF-DNA complex and of the complementary dNTP as defined by template identity.

$$
v=\frac{k_{\text {cat }} \times \mathrm{KF}-\mathrm{DNA} \times \mathrm{dNTP}_{\text {complementary }}}{K_{\mathrm{m}}+\mathrm{dNTP}_{\text {complementary }}}
$$

In the experiments presented in this study, all nucleotides are added in equal starting concentrations. To simplify the analysis further, the sequences of the templates employed have an even ratio of all four dNTPs, which leads approximately to a simultaneous equal reduction of all dNTP types during DNA synthesis. This holds true, as long as the distribution of nucleotides in the sequence is not heavily biased, and the DNA templates were designed accordingly. The model can be easily adapted to work with varying nucleotide concentrations, or with different kinetic parameters at each individual DNA template 
position. Instead of fitting Equation 1 to initial rates, it is integrated together with the rest of the model to produce the full time course. This is a suitable approximation as long as $\mathrm{KF}_{0} /\left(\mathrm{dNTP}+K_{\mathrm{m}}\right) \ll 1(19)$, where $\mathrm{KF}_{0}$ is the initial enzyme concentration. The typical $\mathrm{KF}$ concentration here is $50 \mathrm{nM}$, which is only a tenth of the estimated $K_{\mathrm{m}}$, so the approximation is assumed to hold even in those cases where the dNTP pool is completely depleted.

Generally, previous kinetic models have not accounted for the polymer nature of DNA template. However, if the enzyme is able to dissociate from DNA template before the template end, the decline of available polymer substrate during a reaction is fundamentally different from that of a pooled substrate: In a plot of substrate concentration vs time, the first follows a sigmoidal curve whereas the second declines exponentially. Thus, we included all polymer species in the model and compared it to the results of reduced model approximations.

In the following, the model parameters will first be estimated in a global fit to experimental time course data. The data were collected by varying the amounts of the components KF, DNA and dNTP. Subsequently, experimental data produced at variable oligonucleotide lengths, temperatures and in $\mathrm{D}_{2} \mathrm{O}$ will be analysed.

\section{Methods}

Steady-state assays were performed essentially as described previously using a stopped PG assay (15). All experiments were performed in $10 \mathrm{~mm}$ Tris/ $\mathrm{HCl}, 50 \mathrm{~mm} \mathrm{NaCl}, 10 \mathrm{mM} \mathrm{MgCl}_{2}$, $1 \mathrm{~mm}$ dithiothreitol, $\mathrm{pH} 8.0$ or $\mathrm{pH}^{*} 8.0$ (in the case of solvent KIE measurements performed in $\mathrm{D}_{2} \mathrm{O}$ ) and the reaction temperature was controlled using a circulating water bath.

Reagents. $\mathrm{KF} \mathrm{exo}^{-}$was obtained from New England Biolabs (Hitchin, Hertfordshire, UK), was monitored between batches by SDS/PAGE (single band at $68 \mathrm{kDa}$ ) and its 
concentration was determined spectrophotometrically $\left(\varepsilon_{280}=55450 \mathrm{M}^{-1} \mathrm{~cm}^{-1}\right)(20)$. dNTPs were obtained from Peqlab Ltd (Sarisbury Green, Hampshire, UK). PicoGreen was obtained from Invitrogen (Life Technologies, Paisley, UK) and its concentration was determined by $\varepsilon_{500}=70000 \mathrm{M}^{-1} \mathrm{~cm}^{-1}$ (21). $\mathrm{D}_{2} \mathrm{O}$ was purchased from Goss Scientific Equipment Ltd (Crewe, Cheshire, UK). HPLC-purified DNA oligonucleotides were obtained from Eurofins MWG Operon (London, UK) and were designed to anneal to the $\mathrm{T} 7$ primer, leaving a 30 to 100 nucleotide long 5' overhang. The sequence of the ssDNA region is randomised and has approximately equal ratios of $\mathrm{A}: \mathrm{T}: \mathrm{G}: \mathrm{C}$. No secondary structure is predicted in any of the sequences. All oligonucleotides were annealed by heating a 1:1.2 mixture of oligonucleotide:T7 primer to $95^{\circ} \mathrm{C}$ for $10-15 \mathrm{~min}$, before allowing it to cool to room temperature over at least $45 \mathrm{~min}$. The sequences are given below, with $\|$ indicating the start of the T7 complement:

(i) T7pR30 5'-TACGGATCCATGCTAGTCCATTAGCAGGTG॥CCCTATAGTGAGTC GTATTA-3'

(ii) T7pR50 5'-GTGGACAGTCTGGTATGTAGTCAGGCTCCAGGAGTCGCCTATGC CAACCT\|CCCTATAGTGAGTCGTATTA-3'

(iii) T7pR80 5'-GTAGCTGACTTCTTCACCACATCTACCAAAGTGGGCAGTCTGGT ATGCAGTCAGGCTCCAGGAGTCGCCTATGCCAACCT\|CCCTATAGTGAGTCGTA TTA-3'

(iv) T7pR100 5'-GACTCGAATGTGACTCAGTGATAGCTGACTTCTTCACCACATCT ACCAAAGTGGGCAGTCTGGTATGCAGTCAGGCTCCAGGAGTCGCCTATGCCAA CCT\|CCCTATAGTGAGTCGTATTA-3'

Model setup. The model shown in Scheme 1 was assembled in Copasi (22). In its largest form, 205 species are involved in the reactions: 101 free DNA and 101 enzyme-bound KF-DNA species, free KF, dNTP and $\mathrm{PP}_{\mathrm{i}}$. Although the model was fitted to fluorescence 
data, it was not necessary to include the fluorescent agent PG in the model, because it quenches the reaction immediately when added (15), and the concentration is sufficient to fully saturate the produced dsDNA. Therefore, the amount of dsDNA formed is taken to be directly proportional to the increase in fluorescence signal, $\Delta f$, which measures the difference between the fluorescence emission from PG bound to dsDNA and ssDNA (Eq 2). Further, the amount of dsDNA formed, or dNTP incorporated, is identical to the amount of $\mathrm{PP}_{\mathrm{i}}$ formed, which is a convenient species to track in the computational model. Thus, the experimental signal $F$ is represented by Eq 3. While it is necessary to include an offset proportional to the initial amount of DNA template-primer present, $\mathrm{DNA}_{0}$, the signal from all other species and instrument noise were found to be insignificant (15).

$$
\begin{gathered}
\Delta f=f_{d s}-f_{s s} \\
F=\mathrm{PP}_{\mathrm{i}} \times \Delta f+\mathrm{DNA}_{0} \times f_{0}
\end{gathered}
$$

The initial concentrations of all species, other than the ones declared in the experimental conditions, are zero. To account for a reduced amount of active enzyme in the temperature dependence experiments, the concentration of active $\mathrm{KF}\left(\mathrm{KF}_{\text {active }}\right)$ in the model is determined by scaling the expected enzyme concentration $\left(\mathrm{KF}_{0}\right)$ with a dimensionless parameter $\left(\mathrm{KF}_{\text {mod }}\right): \mathrm{KF}_{\text {active }}=\mathrm{KF}_{0} \times \mathrm{KF}_{\text {mod }}$. The same approach was used to modify the concentration of available template-primer DNA with a dimensionless parameter (DNA $\mathrm{Dod})$ for all data sets: $\mathrm{DNA}_{\text {active }}=\mathrm{DNA}_{0} \times \mathrm{DNA}_{\text {mod. }}$. Seven of the data sets showed a marked improvement in quality of fit when including this modification. Because the fitted parameter was consistently estimated to be lower than $1\left(\mathrm{DNA}_{\bmod }=0.80 \pm 0.06, n=7\right)$, we concluded that the annealing process of primer to oligo was not fully efficient. It is expected this is also true for all other data sets, which do not contain sufficient information to determine $\mathrm{DNA}_{\text {mod}}$. Therefore, we set the parameter to 0.8 when it could not be unambigiously fitted for. 
The model was also set up independently in Mathematica 10.0 (Wolfram Research, Inc., Champaign, IL) employing the NDSolve framework. Because this approach requires entering the differential equations directly, it lends itself to a cross-validation platform for large Copasi models, which take a reaction-centric approach. It was also used to simulate the data analysed in the reduced model approximation and to produce all figures.

Global regression analysis. The model from Scheme 1 was numerically integrated with the LSODA algorithm and was fit to experimental data in Copasi using the standard parameters for each optimisation algorithm. First, an Evolutionary Strategy algorithm was applied (SRES), followed by local optimisation with the gradient-based LevenbergMarquardt algorithm. This procedure was shown to be successful for a number of biological optimisation problems by Rodriguez-Fernandez et al. (23). It should be noted that the same minima were found when applying the faster Hooke-Jeeves direct-search algorithm in tandem with Levenberg-Marquardt.

In the initial calibration, the kinetic parameters $k_{1}, k_{-1}, k_{\text {cat }}$ and $K_{\mathrm{m}}$ were globally fitted to the experimental data sets of KF, DNA and dNTP dependencies. The global optimisation was weighted in order to ensure similar contributions of each data set to the overall objective value. The weights were $1 \mathrm{x}$ for $\mathrm{KF}, 3 \mathrm{x}$ for DNA, and $1 \mathrm{x}$ for $\mathrm{dNTP}$. For all other regressions, kinetic parameters were fixed to the values from this calibration (Table 1), unless they were estimated. The calculated sum of squares and auxiliary parameters $\Delta f, f_{0}, \mathrm{KF}_{\text {mod }}, \mathrm{DNA}_{\text {mod }}$ and $k_{- \text {end }}$ are included in Table S1. While $\Delta f$ and $f_{0}$ are expected to be constants under a given set of conditions, the values change depending on the DNA template employed, fluorometer settings and lamp output. However, the specific values can be readily estimated from the analysis of multiple time courses in a global regression. Note that, if multiple time courses are not available, a standard curve can be constructed to estimate the parameters (15). 
The standard errors of fitted parameters were taken from the Copasi output. The standard errors of parameters which are ratios of fitted parameters were calculated using two different methods: for the KIE, which is a ratio of uncorrelated parameters, Equation 4 was used.

$$
\mathrm{KIE}_{S E}=\frac{X_{\text {Value }}}{Y_{\text {Value }}} \times \sqrt{\left(\frac{X_{S E}}{X_{\text {Value }}}\right)^{2}+\left(\frac{Y_{S E}}{Y_{\text {Value }}}\right)^{2}}
$$

For parameters made from a combination of parameters that have some degree of correlation, such as $k_{\text {cat }} / K_{\mathrm{m}}$ and $K_{\mathrm{d}}$, the standard errors were again estimated in Copasi. This was done by making one of the single parameters dependent on the other two and subsequently fitting for the combined parameter.

Analysis of published data. The model in Scheme V from Dahlberg and Benkovic (13) was implemented in Copasi including all relevant parameters and initial conditions. This model was first used to accurately calculate their implicit steady-state rate and compare the result to our $k_{\text {cat }}$ values. Next, a number of steady-state rate calculations were made for different values of $\mathrm{KIE}_{\text {int }}$ after substituting $k_{4}$ and $k_{-4}$ for $150 / \mathrm{KIE}_{\text {int }} \mathrm{s}^{-1}$ and $37.5 / \mathrm{KIE}_{\text {int }}$ $\mathrm{s}^{-1}$. The values of $\mathrm{KIE}_{\text {int }}$ which corresponded to a 3 to 3.2 -fold drop in the steady-state rate are taken to reflect the $\mathrm{KIE}_{\text {int }}$ of phosphoryl transfer, assuming the model is correct. Finally, the model was numerically integrated and the full time courses were compared and fitted to the pulse-chase/pulse-quench data from their Figure 2 (Figure S2).

\section{Results}

Model Calibration. The presented model in Scheme 1 is designed to produce the time courses of DNA polymerase-catalysed synthesis of dsDNA of arbitrary finite length. Three species are necessarily involved in this process: DNA polymerase, dNTPs and a template-primer strand of DNA forming the initiation locus. The most straightforward test for the model are sets of 
experiments, in which the concentration of one species is varied, while the other two are held constant, and the time course of the polymerisation progress is recorded. Subsequently, the time courses can be analysed with regression methods: if a single time course is analysed, this is referred to as local nonlinear regression. Global nonlinear regression, on the other hand, is performed when multiple time courses, or a set of time courses, at various concentrations of species are analysed simultaneously and model parameters are shared. The sharing of parameters often leads to an increase in confidence of the estimated parameters, which can, in some cases, enable the estimation of novel parameters that can not be determined when fitting the data sets independently. Sharing parameters across the fit of multiple datasets can further reveal inconsistencies in the data or false assumptions in the model, which may have gone unnoticed when analysing data locally (24).

For a simple reaction involving just two species, enzyme and substrate, it would be sufficient to record the time courses at different dNTP concentrations and fit an appropriate model to all of the data points in a global regression analysis. While this is an appropriate method to analyse a one-substrate reaction model, it is insufficient for determining all parameters of a more complex kinetic model such as the one depicted in Scheme 1. For example, if this model is fitted to only one experimental dNTP dependency data set (in which dNTP is the variable component), it would be difficult to determine the polymeraseDNA association rate constant $k_{1}$ and $k_{\text {cat }}$ at the same time, because their behaviour is correlated in the search of the optimal parameter: if $k_{1}$ increases and therefore more enzymebound DNA species are present at any one time, much of the effect on the polymerisation rate can be countered by decreasing $k_{\text {cat }}$, and vice versa. One popular workaround for this particular problem has been to use an excess of DNA polymerase, thus assuming that the concentration of DNA template is identical to the concentration of the active polymerase-DNA complex (14). However, this approach has a number of disadvantages: (i) it may give inaccurate results, because the active polymerase-DNA complex may exist 
in significantly lower quantities than expected throughout the time course; (ii) including necessary assumptions about the polymerase-DNA interaction makes it impossible to gain information on this interaction, such as the calculation of a $K_{\mathrm{d}}$; (iii) it is possible that the system can only be probed in concentration regimes that are not biologically relevant; (iv) if the polymerase-DNA interaction behaves in a more complicated way than assumed, eg due to enzyme dimerisation (25), the model fitting may not necessarily fail, but the computed parameters could be unreliable.

Realising the insufficiency of single dependency experiments, we first fitted three sets of time courses to the model in Scheme 1 in a global regression (Figure 1). In each of these sets, either KF, DNA or dNTP concentration was the variable component, while the other two were held constant. The resulting data set was therefore 5-dimensional; three for species, one for the time point and one for the resulting fluorescence. All of the parameters $k_{1}, k_{-1}$, $k_{\text {cat }}$ and $K_{\mathrm{m}}$ (Table 1 ) were uniquely determined. The combined parameters $k_{\text {cat }} / K_{\mathrm{m}}$ and $K_{\mathrm{d}}=k_{-1} / k_{1}$ were subsequently derived from the results. 



\begin{tabular}{|c|c|c|}
\hline $\mathbf{A}[\mathrm{KF}] / \mathrm{nM}$ & $\mathbf{B}[\mathrm{DNA}] / \mathrm{nM}$ & $\mathbf{C}[\mathrm{dNTP}] / \mu \mathrm{M}$ \\
\hline$\nabla^{-2} 200$ & $\nabla^{-} 50 \nabla^{-} 15$ & - $100 \nabla^{-} 5$ \\
\hline$\square-100$ & ㅁ 40 - 12.5 & $\nabla^{-} 50 \quad \square=3$ \\
\hline$\diamond 50$ & $\diamond 30 \diamond 10$ & $\square-30 \diamond 2$ \\
\hline$\triangle 25$ & $\triangle 25 \triangle 8$ & $\nabla 20 \triangle 1$ \\
\hline \multirow[t]{2}{*}{$a$} & - $-20=0$ & $\triangle 15$ - 0 \\
\hline & & -10 \\
\hline
\end{tabular}

Figure 1. Global calibration fit. The varied component was either (A) KF, (B) T7pR80 DNA template, or $(\mathbf{C})$ dNTP, and the reaction was started by addition of $\mathrm{KF}$ and stopped with $3 \mu \mathrm{M}$ PG. The experiment was conducted in $10 \mathrm{~mm}$ Tris/ $\mathrm{HCl}$, $50 \mathrm{~mm} \mathrm{NaCl}, 10 \mathrm{~mm} \mathrm{MgCl}_{2}, 1 \mathrm{~mm}$ dithiothreitol, $\mathrm{pH} 8.0$ at $25^{\circ} \mathrm{C}$. KF dependence: 0 to $200 \mathrm{nM} \mathrm{KF}, 50 \mathrm{nM}$ T7pR80, $500 \mu \mathrm{M}$ dNTP. T7pR80 dependence: $5 \mathrm{nM} \mathrm{KF}, 0$ to $50 \mathrm{~nm}$ T7pR80, $500 \mu \mathrm{m}$ dNTP. dNTP dependence: $50 \mathrm{~nm} \mathrm{KF}, 100 \mathrm{~nm}$ T7pR80, 0 to $100 \mu \mathrm{M}$ dNTP.

Table 1. Results of global regression of Scheme 1 to the three data sets shown in Figure 1. $k_{1}, k_{-1}$ and $K_{\mathrm{d}}$ refer to the enzyme-template binding parameters, while $k_{\text {cat }}$ and $K_{\mathrm{m}}$ refer to the steady-state parameters of dNTP substrate.

\begin{tabular}{lc}
\hline Parameter & Value \pm Standard Error \\
$k_{1} /\left(\mathrm{\mu M}^{-1} \mathrm{~s}^{-1}\right)$ & $7.4 \pm 1.0$ \\
$k_{-1} / \mathrm{s}^{-1}$ & $0.07 \pm 0.01$ \\
$K_{\mathrm{d}} / \mathrm{nM}$ & $10.0 \pm 1.8$ \\
$k_{\mathrm{cat}} / \mathrm{s}^{-1}$ & $3.3 \pm 0.1$ \\
$K_{\mathrm{m}} / \mu \mathrm{M}$ & $0.51 \pm 0.04$ \\
$k_{\mathrm{cat}} / K_{\mathrm{m}} /\left(\mathrm{\mu M}^{-1} \mathrm{~s}^{-1}\right)$ & $6.5 \pm 0.6$ \\
\hline
\end{tabular}


Reduced model approximation. In the regression analysis above, the model explicitly contains every single polymer species: For example, simulating a 100-mer requires 202 species of DNA and polymerase-DNA species. While this is the most flexible form, because all kinetic parameters at each polymer step can be directly accessed and changed intuitively, some applications may require a computationally less expensive approximation. Examples of such applications include the analysis of longer DNA templates, the addition of multiple enzyme-template states or the calculation of Monte Carlo confidence intervals. Therefore, we constructed a number of reduced models with fewer species. Such models, of polymer length $l_{\text {model }}$, were then compared to the model of the desired oligo length, $l_{\text {target }}$. In the short models, the rate $v_{\text {short }}$ directs the rate of catalysis and the production of $\mathrm{PP}_{\mathrm{i}}$. It is calculated as $v_{\text {short }}=v \times l_{\text {model }} / l_{\text {target }}$. Next, multiple time courses were generated assuming a model with $l_{\text {target }}=100$ and a generic parameter set of $k_{1}=10 \mathrm{~s}^{-1}, K_{\mathrm{d}}=10 \mathrm{nM}, k_{\text {cat }}=5 \mathrm{~s}^{-1}$, $K_{\mathrm{m}}=0.5 \mu \mathrm{M}$. The initial simulation conditions were similar to those used in the experimental calibration experiment (Figure 1). The time course data were fitted using global regression (Figure S1).

It is apparent that fitting a polymer reaction with a monomer model is unsatisfactory, especially if the amount of DNA polymerase is higher than the amount of DNA template. The main time course features can be reproduced by models above a length of 3 . Figure 2 illustrates how the estimated parameters differ from its known value. It is interesting to note that it only requires the simulation of a length 5 polymer to estimate $k_{\text {cat }}$ and $K_{\mathrm{m}}$ within $10 \%$ of their true value. Since many applications involve the incorporation of dNTPs using well-studied enzymes, this could be a useful approximation. In order to determine $k_{1}$ and $K_{\mathrm{d}}$ with a similar accuracy, a model polymer length of 10 to 15 is necessary. As expected, the parameters only result in the true value at a model length of 100, but in many cases half the model length produces indistinguishable results.

Nevertheless, for the following experiments, it was possible to perform each parameter 
regression using the full model in hours on a desktop computer, thus no approximation has been made. The model was used to determine a selection of the kinetic parameters under different conditions, while the remaining parameters were fixed to the values estimated in the calibration above. The novel conditions tested include variation of (i) DNA template length, (ii) temperature and (iii) solvent isotopic content.

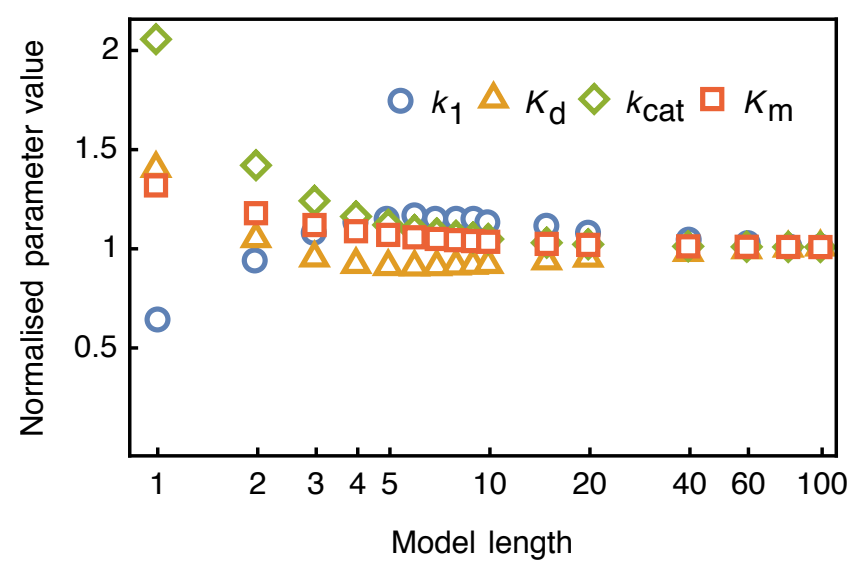

Figure 2. Reduced model approximation of a 100-mer. Global regression estimates depend on the number of explicit DNA species in the model. All parameter results were divided by the corresponding simulation values.

DNA template length dependence. We next investigated whether the model can reproduce the time courses of experiments in which the oligonucleotide length is varied. The oligonucleotides comprised a single-stranded portion of $30,50,80$ or 100 nucleotides. The data were again analysed using global nonlinear regression (Figure 3 ). Interestingly, a $k_{\text {cat }}$ of $2.5 \mathrm{~s}^{-1}$ can be employed to reproduce all of the time courses (Table S2), which indicates that the increase in template length does not significantly increase unproductive binding by interaction with longer single-stranded and completed oligonucleotides. The fit was also significantly better if the dissociation of $\mathrm{KF}\left(k_{-1}\right)$ from the final template position $\left(\mathrm{DNA}_{\mathrm{n}}\right)$ was allowed to differ from its expected value of $0.07 \mathrm{~s}^{-1}$ (Table 1).

The value was estimated to be $1.7 \pm 2.3 \mathrm{~s}^{-1}$ (Table S2), so it is likely that the dissociation of DNA polymerase from completely polymerised DNA is somewhat faster than dissociation from uncompleted template-primer. This effect becomes more important the shorter the 
oligonucleotide is, and may therefore have been hidden in the analysis of the previous experiments with the longer 80-mer template. We thus included a separate $k_{-1}$ for the final dissociation in a later experiment in which T7pR30 template is used again.

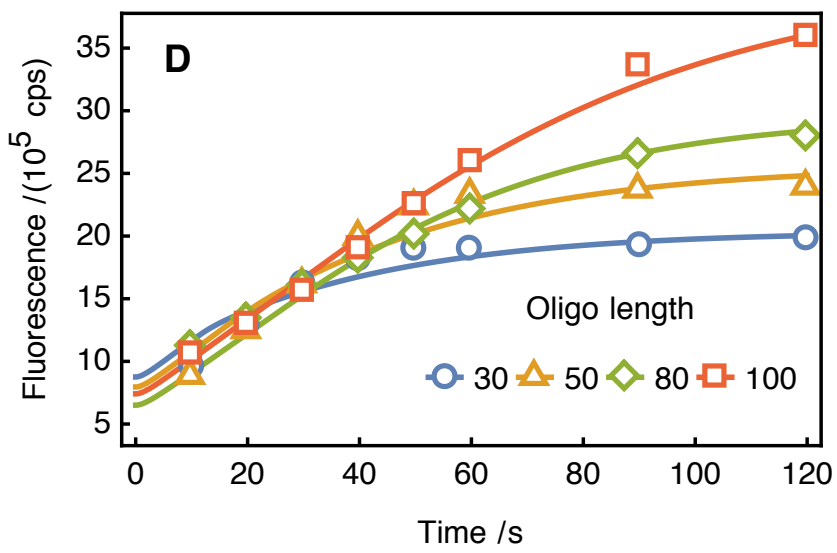

Figure 3. DNA template length dependence fit with a shared $k_{\text {cat }}$ parameter for all data sets. The reaction was started by adding KF and stopped with $3 \mu \mathrm{M} \mathrm{PG}$. The experiment was conducted with $50 \mathrm{~nm} \mathrm{KF}, 100 \mathrm{~nm}$ T7pR30 or T7pR50 or T7pR80 or T7pR100, $500 \mu \mathrm{M}$ dNTP in $10 \mathrm{~mm}$ Tris/HCl, $50 \mathrm{~mm} \mathrm{NaCl}, 10 \mathrm{~mm} \mathrm{MgCl}_{2}, 1 \mathrm{~mm}$ dithiothreitol, $\mathrm{pH} 8.0$ at $25^{\circ} \mathrm{C}$.

Temperature dependence. Brown and LiCata (26) have suggested that KF becomes inactivated at temperatures below approximately $20^{\circ} \mathrm{C}$, while still tightly bound to DNA. We tested whether the Scheme 1 model is able to account for these proposed differences and fitted it to a series of experimental time course data measured under saturating dNTP conditions, in which both KF concentration and temperature were varied. Global regression analyses were performed for data sets at each of the temperatures 5, 10, 15, 20 and $25^{\circ} \mathrm{C}$ (Figure 4). The results show $k_{\text {cat }}$ is a well-determined parameter and decreases from $5.6 \mathrm{~s}^{-1}$ at $25^{\circ} \mathrm{C}$ to $0.43 \mathrm{~s}^{-1}$ at $5^{\circ} \mathrm{C}$. All $k_{\text {cat }}$ values were fitted to the Arrhenius equation, which revealed an activation energy of $82 \pm 10 \mathrm{~kJ} \mathrm{~mol}^{-1}$. This value is in agreement with a previous estimation of $71 \mathrm{~kJ} \mathrm{~mol}^{-1}(8)$.

The factor $\mathrm{KF}_{\text {active }}$ reduces the initial $\mathrm{KF}$ concentration and is an essential part of the model below $20^{\circ} \mathrm{C}$. It is important to note that this reduction in active enzyme concentration 
can not simply be substituted by a reduction in the rate of KF-DNA association $\left(k_{1}\right)$ or a reduction in $k_{\text {cat }}$ (see Discussion).
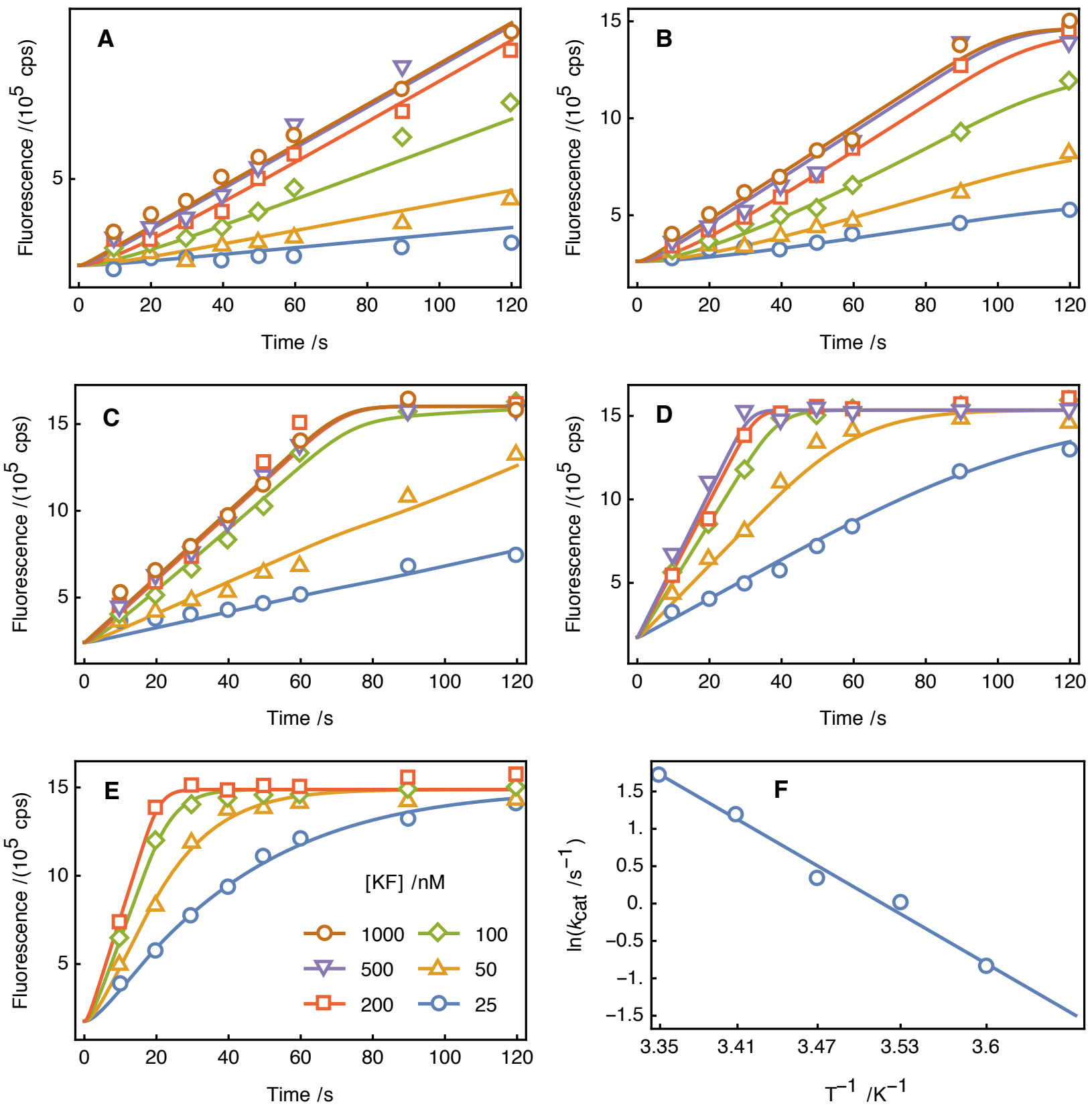

Figure 4. Temperature dependence fits of the reaction at $(\mathbf{A}) 5^{\circ} \mathrm{C},(\mathbf{B}) 10^{\circ} \mathrm{C}$, (C) $15^{\circ} \mathrm{C}$, (D) $20^{\circ} \mathrm{C}$, (E) $25^{\circ} \mathrm{C}$. The reaction was started by adding $\mathrm{KF}$, as given in legend, and stopped with $3 \mu \mathrm{M}$ PG. The experiment was conducted with $50 \mathrm{~nm}$ T7pR100 DNA template, $500 \mu \mathrm{m}$ dNTP in $10 \mathrm{~mm}$ Tris $/ \mathrm{HCl}, 50 \mathrm{~mm} \mathrm{NaCl}$, $10 \mathrm{mM} \mathrm{MgCl}_{2}, 1 \mathrm{mM}$ dithiothreitol, $\mathrm{pH}$ 8.0. (F) Arrhenius plot of $k_{\text {cat }}$ with $E_{a}$ of $82 \pm 10 \mathrm{~kJ} \mathrm{~mol}^{-1}$ and pre-exponential factor $A$ of $1.3 \pm 5.6 \times 10^{16} \mathrm{~s}^{-1}$. 
Initially, the fitted KF binding parameters determined from these enzyme dependencies were underdetermined. At lower temperatures, the inclusion of $k_{-1}$ in the model introduced excessive parameter correlation. The DNA dissociation appears to be sufficiently slow at these lower temperatures as to be apparently irreversible over the experimental timescale. Consequently, DNA binding was made irreversible at temperatures below $20^{\circ} \mathrm{C}$. At all temperatures, the errors in $k_{1}$ and $K_{\mathrm{d}}$ were large, because enzyme dependencies alone do not sufficiently restrain those parameters of the model. At all temperatures, the results for $k_{\text {cat }}$ and $\mathrm{KF}_{\text {active }}$ were nearly identical in both magnitude and trend, irrespective of whether the reversible or irreversible model was fitted.

Table 2. Temperature dependence parameters.

\begin{tabular}{lccccc}
\hline & \multicolumn{5}{c}{ Temperature $/{ }^{\circ} \mathrm{C}$} \\
Parameter & 25 & 20 & 15 & 10 & 5 \\
$k_{1} /\left(\mathrm{\mu M}^{-1} \mathrm{~s}^{-1}\right)$ & $5.5 \pm 2.6$ & $45 \pm 25$ & $17 \pm 7$ & $1.5 \pm 0.3$ & $3.5 \pm 1.0$ \\
$K_{\mathrm{d}} / \mathrm{nM}^{-1}$ & $20 \pm 8$ & $5.6 \pm 1.8$ & $-^{a}$ & $-^{a}$ & ${ }^{a}$ \\
$k_{\text {cat }} / \mathrm{s}^{-1}$ & $5.6 \pm 0.4$ & $3.3 \pm 0.1$ & $1.40 \pm 0.02$ & $1.00 \pm 0.02$ & $0.43 \pm 0.01$ \\
$\mathrm{KF}_{\text {active }} / \mathrm{KF}_{0}{ }^{b}$ & $0.95 \pm 0.17$ & $0.53 \pm 0.04$ & $0.41 \pm 0.02$ & $0.36 \pm 0.03$ & $0.27 \pm 0.01$ \\
\hline${ }^{a}$ not existent in irreversible model. \\
${ }^{b} \mathrm{KF}_{\text {active }} / \mathrm{KF}_{0}$ is the fraction of active enzyme. \\
\hline
\end{tabular}

Solvent isotope effects. The question of how DNA polymerase achieves its extraordinary fidelity has been the subject of intense debate over the past thirty years $(16,17,27,28)$. Fidelity is a concept defined by the kinetic mechanism and parameters involved. For KF, it is assumed that a slow conformational change precedes a fast chemical step, which is then followed again by a slow conformational change step (bracketed part of Scheme 1) $(11,13)$. In this model, the first conformational change is rate-limiting in single-nucleotide incorporation, the phosphoryl transfer reaction (which is the isotopically-sensitive step (29)) is rapid, and the second conformational change is rate-limiting in processive nucleotide incorporation. From this, we would expect the $k_{\text {cat }}$ measured in our experiments to be dominated by the second conformational change. Thus, a change of the solvent from $\mathrm{H}_{2} \mathrm{O}$ to 
$\mathrm{D}_{2} \mathrm{O}$ is expected to have little effect on $k_{\text {cat }}$ and the observed KIE should be close to unity, if the $\mathrm{pH}$ of the $\mathrm{D}_{2} \mathrm{O}$ solution is adjusted to offset the change in $\mathrm{p} K_{\mathrm{a}}$ of relevant ionisable groups upon deuteration $(30,31)$.

We tested this prediction by comparing the polymerisation time courses using T7pR80 template with varying dNTP concentrations in $\mathrm{D}_{2} \mathrm{O}$ at $\mathrm{pH}^{*}$ 8.0, and compared it to the dNTP dependency in $\mathrm{H}_{2} \mathrm{O}$ ( $\mathrm{pH}$ 8.0) presented before (Table 1). Global regression was performed as before (Figure $5 \mathrm{~A}$ ) and the results are shown in Table 3. Contrary to expectations, the $k_{\text {cat }}$ reduces from $3.3 \pm 0.1 \mathrm{~s}^{-1}$ in $\mathrm{H}_{2} \mathrm{O}$ to $1.1 \pm 0.1 \mathrm{~s}^{-1}$ in $\mathrm{D}_{2} \mathrm{O}$, resulting in a KIE obs of $3.0 \pm 0.2$. The $\mathrm{KIE}_{\mathrm{obs}}$ on $K_{\mathrm{m}}$ is of similar magnitude, while the $\mathrm{KIE}_{\mathrm{obs}}$ on $k_{\text {cat }} / K_{\mathrm{m}}$ is nearly unity. These results and the interpretation of the steady-state parameters will be examined in detail in the Discussion.

Next, we investigated if these intriguing results can be replicated with a shorter template, T7pR30. We recorded time courses from dNTP dependencies in $\mathrm{H}_{2} \mathrm{O}$ and $\mathrm{D}_{2} \mathrm{O}$ as before and fitted the Scheme 1 model to the data (Figure 5 B/C). The observed KIEs are not significantly different from those measured with the longer template (Table 3). These experiments clearly demonstrate that there is a $\mathrm{KIE}_{\text {obs }}$ greater than 1 on $k_{\text {cat }}$ and $K_{\mathrm{m}}$ in processive nucleotide incorporation for $\mathrm{KF}$, while the $\mathrm{KIE}$ on the specificity constant $k_{\text {cat }} / K_{\mathrm{m}}$ is close to 1 . 

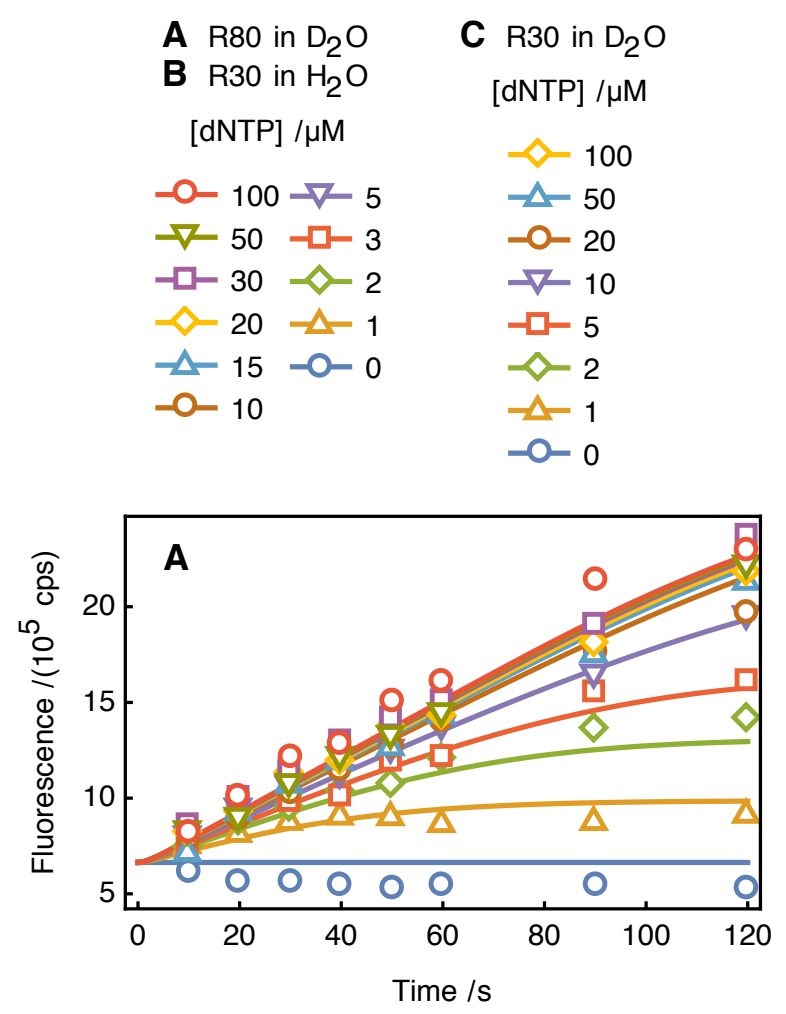
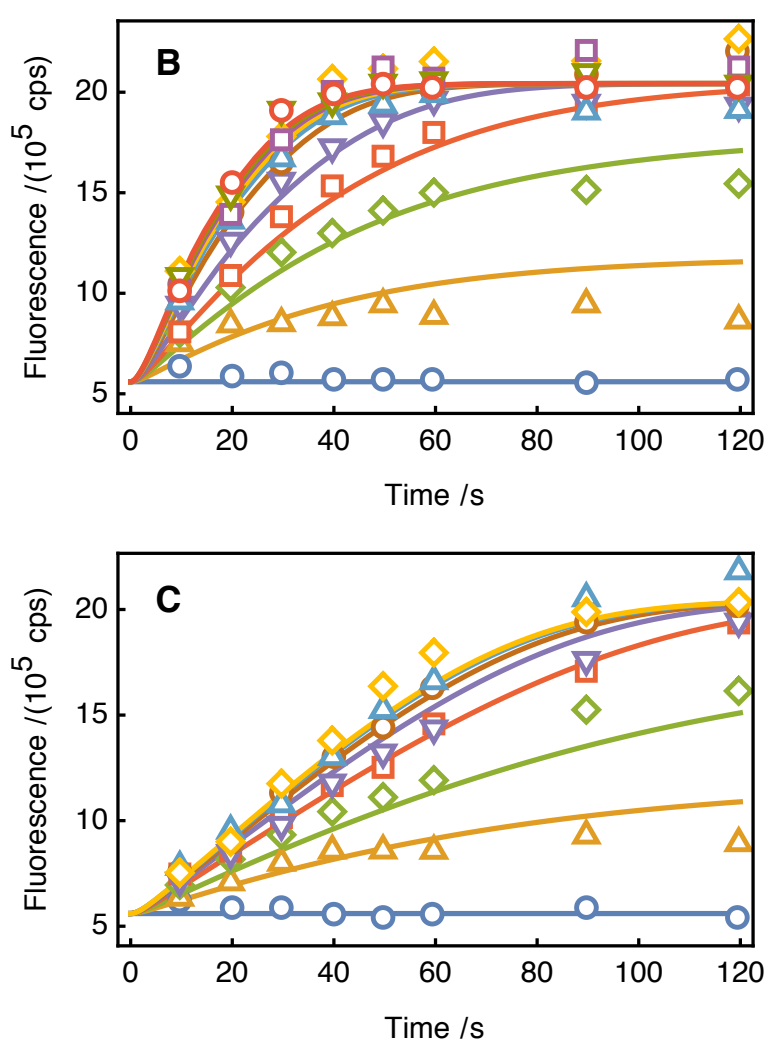

Figure 5. dNTP dependence fits for (A) T7pR80 in $\mathrm{D}_{2} \mathrm{O}$, and for $(\mathbf{B} / \mathbf{C}) \mathrm{T} 7 \mathrm{pR} 30$ in $\mathrm{H}_{2} \mathrm{O}$ and $\mathrm{D}_{2} \mathrm{O}$. The reaction was started by adding $\mathrm{KF}$ and stopped with $3 \mu \mathrm{M}$ PG. The experiment was conducted with $50 \mathrm{~nm} \mathrm{KF}, 100 \mathrm{~nm}$ T7pR80 or T7pR30 DNA template, 0 to $100 \mu \mathrm{M}$ dNTP in $10 \mathrm{~mm}$ Tris/ $\mathrm{HCl}, 50 \mathrm{~mm} \mathrm{NaCl}, 10 \mathrm{~mm} \mathrm{MgCl} 2,1 \mathrm{~mm}$ dithiothreitol, $\mathrm{pH} / \mathrm{pH}^{*} 8.0$ at $25^{\circ} \mathrm{C}$

Table 3. Results of dNTP dependence data regression including solvent $\mathrm{KIE}_{\mathrm{obs}}$ values.

\begin{tabular}{lccc}
\hline $\mathrm{T} 7 \mathrm{pR} 80 \mathrm{DNA}$ & $\mathrm{H}_{2} \mathrm{O}^{a}$ & $\mathrm{D}_{2} \mathrm{O}$ & $\mathrm{KIE}_{\text {obs }}$ \\
\hline$k_{\text {cat }} / \mathrm{s}^{-1}$ & $3.3 \pm 0.1$ & $1.13 \pm 0.06$ & $3.0 \pm 0.2$ \\
$K_{\mathrm{m}} / \mathrm{\mu M}$ & $0.51 \pm 0.04$ & $0.22 \pm 0.03$ & $2.3 \pm 0.3$ \\
$k_{\text {cat }} / K_{\mathrm{m}} /\left(\mathrm{\mu M}^{-1} \mathrm{~s}^{-1}\right)$ & $6.5 \pm 0.6$ & $5.1 \pm 0.7$ & $1.3 \pm 0.2$ \\
\hline $\mathrm{T} 7 \mathrm{pR} 30 \mathrm{DNA}$ & $\mathrm{H}_{2} \mathrm{O}$ & $\mathrm{D}_{2} \mathrm{O}$ & $\mathrm{KIE}_{\text {obs }}$ \\
\hline$k_{\text {cat }} / \mathrm{s}^{-1}$ & $2.6 \pm 0.1$ & $0.83 \pm 0.02$ & $3.2 \pm 0.2$ \\
$K_{\mathrm{m}} / \mathrm{\mu M}$ & $0.86 \pm 0.07$ & $0.40 \pm 0.03$ & $2.2 \pm 0.3$ \\
$k_{\text {cat }} / K_{\mathrm{m}} /\left(\mathrm{\mu M}^{-1} \mathrm{~s}^{-1}\right)$ & $3.1 \pm 0.2$ & $2.1 \pm 0.2$ & $1.5 \pm 0.1$ \\
\hline${ }_{\text {from Table } 1}$ & & & \\
\hline
\end{tabular}




\section{Discussion}

In this paper, we have demonstrated how numerical integration of an enzyme-catalysed polymer model, as shown in Scheme 1, can be used to conveniently analyse time course data of KF-catalysed synthesis of dsDNA of arbitary template length. In the following, the biochemical insight we have gained will be discussed, and some advantages and limitations of the methods will be highlighted.

Polymerase-DNA interaction. The experimental conditions typically used in DNA polymerase assays are chosen in such a way as to allow simplifying assumptions, such as [polymerase] $\gg[\mathrm{DNA}](11,14)$. Of course, when such conditions are used, this can prove useful for the analysis of dNTP incorporation, but such conditions prohibit the analysis of the interactions between polymerase and DNA. For the analysis of these polymerase-DNA interactions, it is mandatory to create conditions in which the concentration of polymerase and DNA are similar, and, under these conditions, assumptions such as permanent saturation of template with enzyme are invalid. One of our key objectives therefore was to account for the enzyme-template interaction by explicitly including it in the model in the form of a simple mass-action binding step.

The DNA-template interaction often systematically distorts the steady-state dNTP incorporation parameters estimated by initial-rate analysis for a number of reasons. Firstly, the DNA binding is 'tight', with previous reports of the $K_{\mathrm{d}}$ to be in the low nM range (11). While a Michaelis-Menten analysis can be performed using a modified quadratic form of the Michaelis-Menten equation (32) to account for tight binding and conditions where

[polymerase] $\simeq[\mathrm{DNA}]$, using this equation often violates the basic assumption that the observed system achieves steady-state rapidly. For example, the maximum amount of KFDNA intermediate in the Scheme 1 model is only reached after 3 to 10 s under the conditions employed here. Even if these complications arising from tight binding were removed, one of 
the key parameters estimated from initial-rate analysis, the DNA $K_{\mathrm{m}}$, is not defined (33) for a processive DNA polymerisation model such as the one depicted in Scheme 1 due to the cancellation of terms arising from the non-replenishment of free KF. Consequently, where we (15) and others (8) have previously used a DNA $K_{\mathrm{m}}$ value to give a phenomenological description of experimental data, these must be interpreted within a model-free framework. Therefore, the analysis of whole time courses is mandatory to extract mechanistic details from processive polymerisation data produced with similar concentrations of KF and DNA template.

We were able to determine an association rate $k_{1}$ of KF-DNA binding of $7.4 \mu \mathrm{M}^{-1} \mathrm{~s}^{-1}$ and a dissociation rate $k_{-1}$ of $0.07 \mathrm{~s}^{-1}$, resulting in a $K_{\mathrm{d}}$ of $10 \mathrm{nM}$ (Table 1 ). The dissociation rate is consistent with previously published values of $0.06 \mathrm{~s}^{-1,}(11)$ or $0.1 \mathrm{~s}^{-1}(10)$. Interestingly, Kuchta et al. (11) and others (34) observed an increase in $k_{-1}$ to $0.67 \mathrm{~s}^{-1}$ as the polymerase acted close to the end of the template, an effect that we also had to include when investigating shorter oligomers in the template length dependency (Figure 3) and dNTP dependency (Figure $5 \mathrm{~B} / \mathrm{C}$ ). However, the large standard errors associated with the estimated values of $0.43 \mathrm{~s}^{-1}$ and $1.67 \mathrm{~s}^{-1}$ (Tables $\mathrm{S} 2$ and $\mathrm{S} 4$ ) prevent the assignment of a reliable rate constant from the available data.

Previous reports of the $K_{\mathrm{d}}$ estimated using pre-steady-state methods are 4.5 to $5 \mathrm{~nm}(11)$ and $5.3 \mathrm{~nm}(13)$, which are comparable to the value estimated here. Similarly, Datta and LiCata (35) report a $K_{\mathrm{d}}$ of $8.1 \mathrm{~nm}$. Others have estimated, using DNase I footprinting, a $K_{\mathrm{d}}$ of $2.1 \mathrm{~nm}(34)$ and $8 \mathrm{nM}(36)$. The authors note that a significant amount of unpaired oligonucleotides present in the reaction mixture could lead to an increase in the estimated $K_{\mathrm{d}}$. This is plausible seeing that the $K_{\mathrm{d}}$ for the binding to unpaired oligos has been reported to be $68 \mathrm{~nm}(37), 40 \mathrm{~nm}(38)$ or as low as $4.9 \mathrm{~nm}(39)$. Thus, some degree of unproductive binding of KF to unpaired oligos, which were present at an amount equal to at least a fifth 
of paired oligos in this study, seems likely. However, more mechanistic details are required in order to include this interaction in a computational model, eg the number of binding sites offered by unpaired oligos. The same is true for unproductive binding on dsDNA; the KF-DNA species in Scheme 1 comprises only the enzyme bound at the end of the templateprimer portion and ready to bind incoming dNTPs, while other dsDNA-bound states along the ssDNA and dsDNA portions certainly exist. The model should thus be improved in the future with mechanistic details regarding the sliding of polymerase along DNA template and unproductive binding.

We were able to demonstrate the importance of unproductive binding when investigating the temperature dependence of the reaction (Figure 4). The best fit to the data was obtained when allowing the concentration of active KF to decrease with decreasing temperature, down to just $27 \%$ at $5{ }^{\circ} \mathrm{C}$ (Table 2). This agrees with previous findings (26), which indicated that $\mathrm{KF}$ becomes inactivated at temperatures around $15^{\circ} \mathrm{C}$, although the binding affinity for template-primer DNA is largely unchanged (40). However, at least for Klentaq polymerase, the $K_{\mathrm{d}}$ for polymerase binding to unpaired oligos decreases from $34 \mathrm{nM}$ at $25^{\circ} \mathrm{C}$ to $22 \mathrm{nM}$ at $5^{\circ} \mathrm{C}(39)$. If this trend applies equally to $\mathrm{KF}$, the decrease in active enzyme species we observe is probably a combination of tighter binding to unpaired oligos, and a shift in enzyme population to inactive states on the ssDNA- and dsDNA portions of template-primer DNA. It was not possible to recognise this feature using initial-rate analysis. As discussed before, the reaction achieves steady-state conditions slowly and one of the key assumptions of initialrate analysis does therefore not hold. However, even if initial-rate analysis was applicable, it would have yielded inferior results: the parameters $k_{1}, k_{\text {cat }}$ and the concentration of KF would be highly correlated, and a reduction of active KF would therefore have gone unnoticed and unknowingly distorted the kinetic parameters. Contrary to initial-rate analysis, the global analysis of full time courses enabled us to reduce the parameter correlations and distinguish the effects of decreased enzyme concentration from the effects on $k_{1}$ and $k_{\text {cat }}$. 
$d N T P$ incorporation parameters $k_{\text {cat }}$ and $K_{\mathrm{m}}$. In the proposed Scheme 1 model of processive DNA polymerisation, the steps involving dNTP binding, orientation, conformational changes, catalysis of phosphoryl transfer, release of products and translocation are convoluted in one step described by steady-state parameters $k_{\text {cat }}$ and $K_{\mathrm{m}}$. In the following, we will first compare the parameters estimated here to previously published values and then discuss their mechanistic interpretation.

The $k_{\text {cat }}$ values determined for different templates were broadly similar at 2.5 to $3.3 \mathrm{~s}^{-1}$ when measured at $25^{\circ} \mathrm{C}$. While this could indicate that the polymerisation rate across the full template length is approximately constant, it could also indicate that the ratio of slow to fast polymerisation regions is similar for the DNA templates investigated. We believe the latter explanation is more likely, which implies that the steady-state parameters values estimated here are averaged values across the entire DNA template. While this is a limitation of the current study, the mathematical model can be easily adapted to treat one, multiple, or all of the $101 k_{\text {cat }}$ and $K_{\mathrm{m}}$ values (for a 100-mer) individually. This level of control can not be obtained using an initial-rate or analytical integration approach, but obviously more data would be required in order to obtain well-defined paramaters. For example, previous polymerase studies have employed sequencing gels to estimate sequential incorporation rates for up to 17 nucleotide incorporations (41-43).

Numerous evidence shows that this flexibility would be required for a complete description of processive polymerisation in order to account for the complex dependence of the nucleotide incorporation rate on nucleotide identity (A, C, G or T) and sequence environment. Early experiments on homopolymers found that $k_{\text {cat }}$ and $K_{\mathrm{m}}$ can differ up to 30-fold for different dNTPs (44). This has, in part, been attributed to the unsuitability of homopolymer templates, because of undesired interactions such as the stacking of T-primers on A- 
templates (41). Additional results have, however, confirmed the importance of sequence on polymerisation rate: Bertram et al. (45) found that both the templating base and neighbouring base greatly affect the $k_{\text {cat }}$ and $K_{\mathrm{m}}$ of dNTP incorporation, while Mytelka and Chamberlin (46) found that T7 DNA polymerase and KF can pause significantly, depending on the environment, during incorporation of dCTP opposite a pyrimidine-G-C site. Maier et al. (47) also found that KF pauses for up to 1000s of seconds during replication of such a sequence. Since the DNA templates we used in this study contain two or more pyrimidineG-C sites, this may explain why the estimated $k_{\text {cat }}$ values are slightly lower than previously estimated rates. Previous measurements of $k_{\text {cat }}$ include $8.3 \mathrm{~s}^{-1}, 5.7 \mathrm{~s}^{-1}, 7.5 \mathrm{~s}^{-1}, 7 \mathrm{~s}^{-1}$, and $5.3 \mathrm{~s}^{-1}(8,11,37,44,47)$. Schwartz and Quake (48) calculated a rate as high as $14 \mathrm{~s}^{-1}$ when subtracting pauses. However, there are also $k_{\text {cat }}$ values near or below the ones reported here from studies which did not involve pyrimidine-G-C replication sequences such as $3.8 \mathrm{~s}^{-1}$, $1.0 \mathrm{~s}^{-1}$ and $2.0 \mathrm{~s}^{-1}(10,49,50)$. The estimated $K_{\mathrm{m}}$ values of $0.51 \mu \mathrm{M}$ (Table 1 ) and $0.86 \mu \mathrm{M}$ (Table 3) reported here are in line with previous estimates of 1 to $2 \mu \mathrm{M}(8), 0.4$ to $1.7 \mu \mathrm{M}$ (49), $1.4 \mu \mathrm{M}(37)$ and $0.58 \mu \mathrm{M}(50)$.

In all conducted experiments, the concentration of non-complementary dNTP is approximately three times higher than the concentration of the complementary dNTP throughout the reaction. KF shows little discrimination in ground-state binding of nucleotides compared to other DNA polymerases (51), so the other nucleotides may act as inhibitors of the reaction. If so, the reported steady-state values become apparent parameters. However, as McClure and Jovin (8) measured a $K_{\mathrm{i}}$ as high as $1 \mathrm{~mm}$ for the inhibitors dGTP or ATP, when dATP is expected, it is not clear whether this translates into a significant change in reaction velocity. Others (13) have also found that ATP does not act as a significant inhibitor. We also found that an increase in non-complementary dATP or dGTP from a 2-fold excess to 12-fold excess did not have any inhibitory effect on the reaction rate (not shown). 
The meaning of $k_{\text {cat }}, k_{\text {cat }} / K_{\mathrm{m}}$ and $K_{\mathrm{m}}$. The interpretation and value of steady-state kinetic parameters for nucleotide incorporation in the study of DNA polymerase has been subject to much debate $(18,52)$. The difficulty arises because DNA polymerase does not catalyse dNTP incorporation in isolation, but only in conjunction with a DNA template and this interaction may mask the kinetic properties of dNTP incorporation. This was shown by Kuchta et al. (11), who investigated the polymerisation of DNA templates with single-nucleotide overhangs by KF. Using initial-rate analysis, they found that $k_{\text {cat }}$ equals the dissociation rate from DNA template, $k_{-1}$. Hence the $k_{\text {cat }}$ did not report on any step involving dNTP incorporation because a far slower step, DNA dissociation, was necessary for the continuous polymerisation process. This criticism of steady-state parameters does not apply to the estimated values in this study because the Scheme 1 model includes the DNA binding steps and thus does not rely on simplifying binding assumptions.

While the presented model is able to separate the DNA binding process, thereby ensuring that the steady-state parameters report on the dNTP incorporation, it is not obvious which microscopic rates of the complex process (bracketed part of Scheme 1) determine the steadystate parameters. In isolation, the presented processive incorporation data do not allow conclusions on this matter. While it is desirable to devise experiments which allow the calculation of some of the microscopic rate constants during observation of the macroscopic replication process under biologically relevant conditions, this may require the use of multiple simultaneous physical probes and large amounts of data. The method of full time course analysis would remain essential for the analysis of more complex experiments. It is worth noting that previously calculated microscopic rates were also derived from full (pre-steadystate) timecourses (14). For further interpretation of the presented data, it is instructive to draw on the rich literature of Klenow fragment. Previous findings have shown that dNTP binding $\left(k_{2}\right)$ is at rapid equilibrium $(4,10)$, although this equilibrium may be coupled and 
result from multiple sequential binding steps, as suggested for T4 DNA polymerase (53). The first conformational change $\left(k_{3}\right)$ occurs at $50 \mathrm{~s}^{-1}$, the phosphoryl transfer $\left(k_{4}\right)$ at a minimum of $150 \mathrm{~s}^{-1}$, the second conformational change $\left(k_{5}\right)$ at $15 \mathrm{~s}^{-1}$, and the release of $\mathrm{PP}_{\mathrm{i}}\left(k_{6}\right)$ is essentially instantaneous $(11,13)$. The slowest of these rates, the second conformational change at $15 \mathrm{~s}^{-1}$ is thus assumed to dominate the $k_{\text {cat }}$ we estimate. While others $(47)$ have approximated these two rates to be identical, an improved rough calculation of the steadystate rate is:

$$
k_{\text {cat }}=\left(1 /\left(K_{4} k_{5}\right)+1 / k_{5}+1 / k_{3}\right)^{-1}=9.7 \mathrm{~s}^{-1}
$$

A thorough steady-state calculation including all steps and conditions used in the study returns $9.3 \mathrm{~s}^{-1}$. As described above, sequence-dependent pausing could account for the 3fold difference to our estimated $k_{\text {cat }}$ values.

The contributions of microscopic parameters to the $K_{\mathrm{m}}$ value are even more difficult to disentangle. Due to the separation of dNTP binding and rate-limiting step, the $K_{\mathrm{m}}$ does not have an obvious relation to the binding affinity of the polymerase-DNA complex for dNTP and is therefore of little use (14). This problematic gap between substrate binding and slow step has been treated more generally by Northrop (54), who advises against the use of $K_{\mathrm{m}}$ for such mechanisms. Although we report the $K_{\mathrm{m}}$ values for comparison purposes, we follow his recommendation and instead focus on $k_{\text {cat }} / K_{\mathrm{m}}$. This is the rate constant for the capture of a productive complex committed to turnover and can, in contrast to $K_{\mathrm{m}}$, be intuitively applied to the mechanism of KF. In Scheme $1, k_{\text {cat }} / K_{\mathrm{m}}$ refers to the rate of formation of the fraction of KF-DNA ${ }_{n}-d N T P$, which will eventually form the product KF-DNA $A_{n+1}$ and free $\mathrm{PP}_{\mathrm{i}} . k_{\mathrm{cat}} / K_{\mathrm{m}}$ further possesses special significance for DNA polymerase, because the value of $k_{\text {cat }} / K_{\mathrm{m}}$ for correct incorporations divided by its value for misincorporations defines the fidelity of the enzyme, one of the key characteristics of DNA polymerases. This idea was put forward by Fersht (55), and was later validated by Bertram et al. (45) in both steady-state and pre-steady-state experiments. 
Interpretation of observed KIEs. The observed solvent deuterium KIEs on $k_{\text {cat }}$ using either $\mathrm{T} 7 \mathrm{pR} 80$ or $\mathrm{T} 7 \mathrm{pR} 30$ template were 3.0 and 3.2 , respectively. These results are similar to previous findings (29), where a $\mathrm{KIE}_{\text {obs }}$ of 2 to 5 was found for poliovirus RNA polymerase, RB69 DNA polymerase, T7 RNA polymerase and HIV reverse transcriptase. The reported measurements were made in the pre-steady-state and the authors surmise that phosphoryl transfer is partially rate-limiting for those polymerases. It is therefore surprising that a similar $\mathrm{KIE}_{\mathrm{obs}}$ is found for KF. For KF, the chemical step $\left(k_{4}\right)$ is assumed to be much faster than both conformational change rates $\left(k_{3}\right.$ and $\left.k_{5}\right)$, which are assumed to be insensitive to isotopic subsitution. It is perhaps even more surprising that the $\mathrm{KIE}_{\mathrm{obs}}$ is measured in the steady-state, because the second conformational change is even slower than the first conformational change (13).

The published model of Dahlberg and Benkovic (13) (bracketed part of Scheme 1) can be used to give an estimate of the intrinsic KIE on the phosphoryl transfer step $\left(k_{4}\right)$. In order to achieve a 3 -fold reduction in the steady-state rate $k_{\text {cat }}$ (ie a $\mathrm{KIE}_{\text {obs }}$ of 3 ), the $\mathrm{KIE}_{\text {int }}$ would have to be 30 to 40 or more. KIEs of this magnitude have been reported for reactions involving a large degree of hydrogen tunnelling (56). Alternatively, our data may suggest that the rate of phosphoryl transfer step is of the same order as the steady-state rate. This would contradict previous findings (13), so it seems appropriate to review the evidence arguing for a fast chemical step flanked by two slow conformational changes.

The initial proposal of a fast phosphoryl transfer step was based on a small elemental effect of 4 to 7 on the polymerisation rate when a nonbridging oxygen on the $\alpha$-phosphate was replaced with a sulfur atom (11). However, this line of evidence was since shown to be unreliable $(57)$, which led others (27) to argue that the highest energy barrier is posed during the chemical step. This mechanism was proposed for DNA polymerase $\beta$ 
based on fluorescence studies (58), and is also supported by the theoretical reasoning that such a mechanism would account for a stronger discrimination between correct and incorrect dNTPs than the previous model $(11,12)$. However, for some polymerases, the strongest evidence comes from pulse-chase/pulse-quench experiments (16). In this type of experiment, the polymerisation reaction was either chased with an excess of unlabeled substrate or quenched with acid after a certain amount of time. Subsequently, the yield of labeled dNTP incorporation was compared between the experiments. The idea is that the yield of pulse-chase experiments is only higher if a pre-chemistry species has locked in the substrate and then proceeds with its incorporation despite an excess of unlabeled competition in the surroundings. When adding acid, on the other hand, all reactions simply stop due to denaturation of the polymerase. For KF, the pulse-chase yield was approximately $20 \%$ higher than the pulse-quench yield, which was interpreted as requiring two slow conformational changes, both before and after the chemical step (13). Further evidence for a slow conformational pre-chemistry step comes from studies employing fluorescent probes (59-61). For example, Purohit et al. (59) found that the signal referring to the putatitive rate-limiting step still occurs when using dideoxy-terminated primer, a non-potent substrate. This is interpreted as evidence for a rate-limiting conformational change step before phosphoryl transfer. It is not obvious what the nature of this conformational change is, although the extensive domain movement of fingers-closing, which predominantly occurs after dNTP binding, was ruled out. FRET studies have shown that it occurs at a rate of $>1000 \mathrm{~s}^{-1}$ or 100 to $300 \mathrm{~s}^{-1}$, much faster than the rate of incorporation measured at 30 to $40 \mathrm{~s}^{-1}$ $(59,60)$. While Bakhtina et al. (62) confirm the rapid rate for the subdomain closure and the identity of a slow post-chemistry conformational change, their results from fluorescence studies contradict the idea of a slow conformational change preceding chemistry. When using dideoxy-terminated primer, they do not record a fluorescence transient which supposedly reports on the rate-limiting step. Further, they argue that the aforementioned pulsechase/pulse-quench data only indicate the presence of a closed KF*-DNA-dNTP species, 
but the chemistry step could still be rate-limiting. This situation was shown to be true for T7 DNA polymerase (63), for which the forward conformational change step is faster than chemistry, but the slow reverse conformational change rate is sufficiently slow so that the yield in a pulse-chase/pulse-quench experiment differs markedly.

In light of this important controversy, it seemed appropriate to revisit the original pulse-chase/pulse-quench experiment for KF (13). The published model was numerically integrated and fitted to the published data. The results show that a difference in pulsechase/pulse-quench yield can occur if the rate of the chemical step is rate-limiting and the reverse rate of the first conformational change is not fast, as suggested by Bakhtina et al. (62). Further, while it is not possible to uniquely determine all parameters, we found that it is at least possible to describe the data (Figure S2) if a pre-chemistry step is of the same magnitude as the phosphoryl transfer step $\left(150 \mathrm{~s}^{-1}\right)$. Putting together these different strands of evidence, it is currently not clear whether the chemical step is rapid or partially rate-limiting. By extension, further investigation is required to confirm whether the $\mathrm{KIE}_{\text {int }}$ on the phosphoryl transfer step is at least 30 to 40 or lower.

The observed solvent deuterium KIEs on $k_{\text {cat }} / K_{\mathrm{m}}$ using either T7pR80 or T7pR30 were 1.3 and 1.5, respectively. This finding can be rationalised by taking into account a theoretical model for the specificity constant for T7 DNA polymerase. Johnson (18) suggests that $k_{3} / K_{\mathrm{d} \text {,dNTP }}$ alone defines the specificity constant if dNTP binding is at rapid equilibrium and the reverse rate of the pre-chemistry conformational change is much slower than the chemical rate, $k_{-3} \ll k_{4}$. Notably, the definition does not include the rate of the chemical step. We propose that this approximation can be made for KF too, which explains why subsitution of solvent for $\mathrm{D}_{2} \mathrm{O}$ does not have a strong effect on $k_{\text {cat }} / K_{\mathrm{m}}$. The small KIEs we observe are thus either due to statistical error, or because the reduced phosphoryl transfer rate in $\mathrm{D}_{2} \mathrm{O}$ starts to approach the magnitude of the reverse rate of the conformational 
change, thus breaking one of the two assumptions discussed above (18). Further, taking into account our previous definition of $k_{\mathrm{cat}} / K_{\mathrm{m}}$ as the rate constant for the capture of productive complex generation, the result is intuitive. As long as the reverse rate of the first conformational change is slow with regards to the following steps, none of these are relevant for the enzyme's specificity. The enzyme locks in a substrate and rarely returns it, independent of the time it takes for subsequent steps. This kinetic model should be applicable to both KF and T7 DNA polymerase alike, even though the latter has a much higher forward rate for the first conformational change $\left(660 \mathrm{~s}^{-1}\right)$ and no rate-limiting postchemistry step (18). Notably, KIEs of around 3 on $k_{\text {cat }}$ and unity for $k_{\text {cat }} / K_{\mathrm{m}}$ have been observed before in studies of the human enzyme carbonic anhydrase II (64). The authors proposed a rate-limiting proton transfer step after the first irreversible step to explain the result, analogous to our own findings presented here.

Applications. The presented model emphasises the complete process of dynamic enzyme binding and repeated dNTP incorporations on a polymer template. This enables the analysis of complex processes, which are difficult to investigate under single-turnover conditions (65). This includes the translocation step (14), for which models have been developed and could be tested (66). Other applications include the analysis of replication at pausing sites or blocks such as pyrimidine dimers. Further, PCR is a key technology that relies on the processive polymerisation of a wide variety of DNA templates by engineered DNA polymerases. In order to compare and improve these polymerases, it is necessary to characterise them with models that account for the processive nature of the target task. In addition, the cycle run times could be more easily optimised if the process can be simulated using a bottom-up approach. Our finding that a long polymer, or a portion of the polymer, can be approximated by a simulated polymer of reduced length could prove useful in this regard. However, such approximations should be made with care if the enzyme system is not very well-known. 
A further challenge in polymerase research arises from the fact that the process is in reality a highly stochastic process, whereas it is not usually treated as such. For example, it was found in a KF single-molecule study that the incorporation rate of the first nucleotide replication rate varies between 1 and $50 \mathrm{~s}^{-1}$ (48). While this topic was not covered here, this behaviour could be readily produced using the mathematical model presented here. Instead of calculating the deterministic solution to the system of ODEs, as performed here, a stochastic solution could be calculated by employing Gillespie's exact method (67) or an approximate stochastic method.

\section{Conclusions}

DNA polymerase-catalysed DNA polymerisation is a complex process, which is often inadequately described by initial-rate analysis using steady-state assumptions (18, 52). In this study, we have described the analysis of full reaction time courses by numerical integration of rate equations. The rate equations are in the form of a system of ODEs, which combines mass-action kinetics of enzyme-template binding, Michaelis-Menten-type incorporation of dNTPs, and a finite DNA template length. Global regression analysis of this model allowed the estimation of $k_{1}, k_{-1}, K_{\mathrm{d}}, k_{\mathrm{cat}}, K_{\mathrm{m}}$ and $k_{\text {cat }} / K_{\mathrm{m}}$ from experimental fluorescence data in good agreement with previously published values (Table 1). The KFtemplate binding interactions could not have been investigated with a steady-state approach due to its tight binding.

It was shown that the model can be used to describe the reaction at a range of temperatures, and that $\mathrm{KF}$ increasingly adopts inactive states when the temperature is lowered (Table 2), as suggested previously (26). However, it is not clear whether the shift to these states occurs at the template-primer junction or not. An alternative explanation for 
our observations is the dimerisation of Klenow fragment, with changing dimer properties at lower temperatures. There is both evidence for (25) and against (38, 39) KF dimerisation occurring on DNA templates. It would be interesting to investigate whether this putative interaction induces changes that can be observed in a suitable kinetic experiment.

Unexpectedly, a KIE of around 3 was observed on both $k_{\text {cat }}$ and $K_{\mathrm{m}}$ under processive polymerisation conditions in $\mathrm{D}_{2} \mathrm{O}$. It was concluded that either proton tunnelling makes a large contribution to the reaction rate, or that phosphoryl transfer is at least partially rate-limiting for $\mathrm{KF}$, contrary to previous findings $(13,16)$. More investigations are required. For example, it could be instructive to determine the $\mathrm{KIE}_{\mathrm{obs}}$ on the first dNTP incorporation using pre-steady-state methods in order to remove the complexities of a second conformational change.

Systems of rate equations have always had the advantage of being simple to set up, intuitive to modify and reliant on fewer assumptions than the corresponding initial-rate approximation. With recent advances in computer hardware and software, most enzyme systems can now be numerically integrated at a speed that allows the estimation of parameters from time course data. This ability should be harnessed, especially for complex enzymes such as DNA polymerase.

\section{Supporting Information Available}

Assay procedure and initial conditions; full results tables; analysis of pulse-chase/pulsequench data; Mathematica code for model generation. This material is available free of charge via the Internet at http://pubs.acs.org/. 


\section{Funding}

This work was funded by the UK British Biological Sciences Research Council $(\mathrm{BB} / \mathrm{H} 021523 / 1)$.

\section{References}

1. Steitz, T. A. (1999) DNA Polymerases: Structural Diversity and Common Mechanisms. Journal of Biological Chemistry 274, 17395-17398.

2. Kornberg, A., and Baker, T. A. DNA replication; W. H. Freeman: San Francisco, 1980.

3. Derbyshire, V., Freemont, P. S., Sanderson, M. R., Beese, L., Friedman, J. M., Joyce, C. M., and Steitz, T. A. (1988) Genetic and crystallographic studies of the 3',5'exonucleolytic site of DNA polymerase I. Science 240, 199-201.

4. Eger, B. T., Kuchta, R. D., Carroll, S. S., Benkovic, P. A., Dahlberg, M. E., Joyce, C. M., and Benkovic, S. J. (1991) Mechanism of DNA replication fidelity for three mutants of DNA polymerase I: Klenow fragment $\mathrm{KF}(\mathrm{exo}+), \mathrm{KF}(\mathrm{polA} 5)$, and $\mathrm{KF}(\mathrm{exo}-)$. Biochemistry 30, 1441-1448.

5. Simha, R., Zimmerman, J. M., and Moacanin, J. (1963) Polymerization Kinetics of Biological Macromolecules on Templates. The Journal of Chemical Physics 39, 12391246.

6. Pipkin, A. C., and Gibbs, J. H. (1966) Kinetics of synthesis and/or conformational changes of biological macromolecules. Biopolymers 4, 3-15.

7. Maniloff, J. (1969) Theoretical considerations of biopolymer synthesis. Journal of Theoretical Biology 23, 441-454. 
8. McClure, W. R., and Jovin, T. M. (1975) The steady state kinetic parameters and nonprocessivity of Escherichia coli deoxyribonucleic acid polymerase I. Journal of Biological Chemistry 250, 4073-4080.

9. McClure, W. R., and Chow, Y. (1979) The kinetics and processivity of nucleic acid polymerases. Methods in Enzymology 64, 277-297.

10. Bryant, F. R., Johnson, K. A., and Benkovic, S. J. (1983) Elementary steps in the DNA polymerase I reaction pathway. Biochemistry 22, 3537-3546.

11. Kuchta, R. D., Mizrahi, V., Benkovic, P. A., Johnson, K. A., and Benkovic, S. J. (1987) Kinetic mechanism of DNA polymerase I (Klenow). Biochemistry 26, 8410-8417.

12. Kuchta, R. D., Benkovic, P., and Benkovic, S. J. (1988) Kinetic mechanism whereby DNA polymerase I (Klenow) replicates DNA with high fidelity. Biochemistry 27, 67166725 .

13. Dahlberg, M. E., and Benkovic, S. J. (1991) Kinetic mechanism of DNA polymerase I(Klenow fragment): identification of a second conformational change and evaluation of the internal equilibrium constant. Biochemistry 30, 4835-4843.

14. Joyce, C. M. (2010) Techniques used to study the DNA polymerase reaction pathway. Biochimica et Biophysica Acta 1804, 1032-1040.

15. Driscoll, M. D., Rentergent, J., and Hay, S. (2014) A quantitative fluorescence-based steady-state assay of DNA polymerase. FEBS Journal 281, 2042-2050.

16. Joyce, C. M., and Benkovic, S. J. (2004) DNA Polymerase Fidelity: Kinetics, Structure, and Checkpoints. Biochemistry 43, 14317-14324.

17. Mizrahi, V., Henrie, R. N., Marlier, J. F., Johnson, K. A., and Benkovic, S. J. (1985) Rate-limiting steps in the DNA polymerase I reaction pathway. Biochemistry 24, 40104018. 
18. Johnson, K. A. (2010) The kinetic and chemical mechanism of high-fidelity DNA polymerases. Biochimica et Biophysica Acta 1804, 1041-1048.

19. Segel, L. A. (1988) On the validity of the steady state assumption of enzyme kinetics. Bulletin of Mathematical Biology 50, 579-593.

20. Joyce, C. M., and Grindley, N. D. (1983) Construction of a plasmid that overproduces the large proteolytic fragment (Klenow fragment) of DNA polymerase I of Escherichia coli. Proceedings of the National Academy of Sciences 80, 1830-1834.

21. Singer, V. L., Jones, L. J., Yue, S. T., and Haugland, R. P. (1997) Characterization of PicoGreen reagent and development of a fluorescence-based solution assay for doublestranded DNA quantitation. Analytical Biochemistry 249, 228-238.

22. Hoops, S., Sahle, S., Gauges, R., Lee, C., Pahle, J., Simus, N., Singhal, M., Xu, L., Mendes, P., and Kummer, U. (2006) COPASI-a COmplex PAthway SImulator. Bioinformatics 22, 3067-3074.

23. Rodriguez-Fernandez, M., Mendes, P., and Banga, J. R. (2006) A hybrid approach for efficient and robust parameter estimation in biochemical pathways. Biosystems 83, 248265.

24. Motulsky, H., and Christopoulos, A. Fitting models to biological data using linear and nonlinear regression: a practical guide to curve fitting; Oxford University Press, 2004.

25. Bailey, M. F., Van der Schans, E. J. C., and Millar, D. P. (2007) Dimerization of the Klenow Fragment of Escherichia coli DNA Polymerase I Is Linked to Its Mode of DNA Binding. Biochemistry 46, 8085-8099.

26. Brown, H. S., and LiCata, V. J. (2013) Enthalpic switch-points and temperature dependencies of DNA binding and nucleotide incorporation by Pol I DNA polymerases. Biochimica et Biophysica Acta 1834, 2133-2138. 
27. Showalter, A. K., and Tsai, M.-D. (2002) A Reexamination of the Nucleotide Incorporation Fidelity of DNA Polymerases. Biochemistry 41, 10571-10576.

28. Oertell, K., Harcourt, E. M., Mohsen, M. G., Petruska, J., Kool, E. T., and Goodman, M. F. (2016) Kinetic selection vs. free energy of DNA base pairing in control of polymerase fidelity. Proceedings of the National Academy of Sciences 113, E2277-E2285.

29. Castro, C., Smidansky, E., Maksimchuk, K. R., Arnold, J. J., Korneeva, V. S., Götte, M., Konigsberg, W., and Cameron, C. E. (2007) Two proton transfers in the transition state for nucleotidyl transfer catalyzed by RNA- and DNA-dependent RNA and DNA polymerases. Proceedings of the National Academy of Sciences 104, 4267-4272.

30. Roberts, G. C. K. NMR of Macromolecules; IRL Press at Oxford University Press, 1993.

31. Scheller, K. H., Scheller-Krattiger, V., and Martin, R. B. (1981) Equilibriums in solutions of nucleosides, 5'-nucleotides, and diethylenetriaminepalladium $(2+)$. Journal of the American Chemical Society 103, 6833-6839.

32. Morrison, J. F. (1982) The slow-binding and slow, tight-binding inhibition of enzymecatalysed reactions. Trends in Biochemical Sciences 7, 102-105.

33. NC-IUB, (1983) Symbolism and terminology in enzyme kinetics. Recommendations 1981. Biochemical Journal 213, 561-571.

34. Turner, R. M., Grindley, N. D. F., and Joyce, C. M. (2003) Interaction of DNA Polymerase I (Klenow Fragment) with the Single-Stranded Template beyond the Site of Synthesis. Biochemistry 42, 2373-2385.

35. Datta, K., and LiCata, V. J. (2003) Salt Dependence of DNA binding by Thermus aquaticus and Escherichia coli DNA Polymerases. Journal of Biological Chemistry 278, $5694-5701$. 
36. Polesky, A. H., Steitz, T. A., Grindley, N. D., and Joyce, C. M. (1990) Identification of residues critical for the polymerase activity of the Klenow fragment of DNA polymerase I from Escherichia coli. Journal of Biological Chemistry 265, 14579-14591.

37. Kukreti, P., Singh, K., Ketkar, A., and Modak, M. J. (2008) Identification of a New Motif Required for the 3'-5' Exonuclease Activity of Escherichia coli DNA Polymerase I (Klenow Fragment). Journal of Biological Chemistry 283, 17979-17990.

38. Datta, K., Johnson, N. P., LiCata, V. J., and von Hippel, P. H. (2009) Local Conformations and Competitive Binding Affinities of Single- and Double-stranded Primer-Template DNA at the Polymerization and Editing Active Sites of DNA Polymerases. Journal of Biological Chemistry 284, 17180-17193.

39. Wowor, A. J., Datta, K., Brown, H. S., Thompson, G. S., Ray, S., Grove, A., and LiCata, V. J. (2010) Thermodynamics of the DNA Structural Selectivity of the Pol I DNA Polymerases from Escherichia coli and Thermus aquaticus. Biophysical Journal 98, 3015-3024.

40. Datta, K., Wowor, A. J., Richard, A. J., and LiCata, V. J. (2006) Temperature Dependence and Thermodynamics of Klenow Polymerase Binding to Primed-Template DNA. Biophysical Journal 90, 1739-1751.

41. Patel, S. S., Wong, I., and Johnson, K. A. (1991) Pre-steady-state kinetic analysis of processive DNA replication including complete characterization of an exonucleasedeficient mutant. Biochemistry 30, 511-525.

42. Kati, W. M., Johnson, K. A., Jerva, L. F., and Anderson, K. S. (1992) Mechanism and fidelity of HIV reverse transcriptase. Journal of Biological Chemistry 267, 25988-25997.

43. Jin, Z., Leveque, V., Ma, H., Johnson, K. A., and Klumpp, K. (2012) Assembly, Purification, and Pre-steady-state Kinetic Analysis of Active RNA-dependent RNA Polymerase Elongation Complex. Journal of Biological Chemistry 287, 10674-10683. 
44. Travaglini, E. C., Mildvan, A. S., and Loeb, L. A. (1975) Kinetic analysis of Escherichia coli deoxyribonucleic acid polymerase I. Journal of Biological Chemistry 250, 8647-8656.

45. Bertram, J. G., Oertell, K., Petruska, J., and Goodman, M. F. (2010) DNA Polymerase Fidelity: Comparing Direct Competition of Right and Wrong dNTP Substrates with Steady State and Pre-Steady State Kinetics. Biochemistry 49, 20-28.

46. Mytelka, D. S., and Chamberlin, M. J. (1996) Analysis and Suppression of DNA Polymerase Pauses Associated with a Trinucleotide Consensus. Nucleic Acids Research 24, 2774-2781.

47. Maier, B., Bensimon, D., and Croquette, V. (2000) Replication by a single DNA polymerase of a stretched single-stranded DNA. Proceedings of the National Academy of Sciences 97, 12002-12007.

48. Schwartz, J. J., and Quake, S. R. (2009) Single molecule measurement of the "speed limit" of DNA polymerase. Proceedings of the National Academy of Sciences 106, 20294-20299.

49. Astatke, M., Grindley, N. D. F., and Joyce, C. M. (1995) Deoxynucleoside Triphosphate and Pyrophosphate Binding Sites in the Catalytically Competent Ternary Complex for the Polymerase Reaction Catalyzed by DNA Polymerase I (Klenow Fragment). Journal of Biological Chemistry 270, 1945-1954.

50. Langer, A., Schräml, M., Strasser, R., Daub, H., Myers, T., Heindl, D., and Rant, U. (2015) Polymerase/DNA interactions and enzymatic activity: multi-parameter analysis with electro-switchable biosurfaces. Scientific Reports 5.

51. Capson, T. L., Peliska, J. A., Kaboord, B. F., Frey, M. W., Lively, C., Dahlberg, M., and Benkovic, S. J. (1992) Kinetic characterization of the polymerase and exonuclease activities of the gene 43 protein of bacteriophage T4. Biochemistry 31, 10984-10994. 
52. Estep, P. A., and Johnson, K. A. (2011) Effect of the Y955C Mutation on Mitochondrial DNA Polymerase Nucleotide Incorporation Efficiency and Fidelity. Biochemistry 50, 6376-6386.

53. Hariharan, C., Bloom, L. B., Helquist, S. A., Kool, E. T., and Reha-Krantz, L. J. (2006) Dynamics of Nucleotide Incorporation: Snapshots Revealed by 2-Aminopurine Fluorescence Studies. Biochemistry 45, 2836-2844.

54. Northrop, D. B. (1998) On the Meaning of Km and V/K in Enzyme Kinetics. Journal of Chemical Education 75, 1153.

55. Fersht, A. Structure and mechanism in protein science: a guide to enzyme catalysis and protein folding; W. H. Freeman: New York, 1999.

56. Allemann, R. K., and Scrutton, N. S. Quantum tunnelling in enzyme-catalysed reactions; Royal Society of Chemistry, 2009.

57. Herschlag, D., Piccirilli, J. A., and Cech, T. R. (1991) Ribozyme-catalyzed and nonenzymic reactions of phosphate diesters: rate effects upon substitution of sulfur for a nonbridging phosphoryl oxygen atom. Biochemistry 30, 4844-4854.

58. Dunlap, C. A., and Tsai, M.-D. (2002) Use of 2-Aminopurine and Tryptophan Fluorescence as Probes in Kinetic Analyses of DNA Polymerase $\beta$. Biochemistry 41, $11226-11235$.

59. Purohit, V., Grindley, N. D. F., and Joyce, C. M. (2003) Use of 2-Aminopurine Fluorescence To Examine Conformational Changes during Nucleotide Incorporation by DNA Polymerase I (Klenow Fragment). Biochemistry 42, 10200-10211.

60. Joyce, C. M., Potapova, O., DeLucia, A. M., Huang, X., Basu, V. P., and Grindley, N. D. F. (2008) Fingers-Closing and Other Rapid Conformational Changes in DNA 
Polymerase I (Klenow Fragment) and Their Role in Nucleotide Selectivity. Biochemistry $47,6103-6116$.

61. Santoso, Y., Joyce, C. M., Potapova, O., Reste, L. L., Hohlbein, J., Torella, J. P., Grindley, N. D. F., and Kapanidis, A. N. (2010) Conformational transitions in DNA polymerase I revealed by single-molecule FRET. Proceedings of the National Academy of Sciences 10\%, 715-720.

62. Bakhtina, M., Roettger, M. P., Kumar, S., and Tsai, M.-D. (2007) A Unified Kinetic Mechanism Applicable to Multiple DNA Polymerases. Biochemistry 46, 5463-5472.

63. Tsai, Y.-C., and Johnson, K. A. (2006) A New Paradigm for DNA Polymerase Specificity. Biochemistry 45, 9675-9687.

64. Steiner, H., Jonsson, B.-H., and Lindskog, S. (1975) The Catalytic Mechanism of Carbonic Anhydrase. European Journal of Biochemistry 59, 253-259.

65. Johnson, K. A. (1993) Conformational Coupling in DNA Polymerase Fidelity. Annual Review of Biochemistry 62, 685-713.

66. Guajardo, R., and Sousa, R. (1997) A model for the mechanism of polymerase translocation. Journal of Molecular Biology 265, 8-19.

67. Gillespie, D. T. (1977) Exact stochastic simulation of coupled chemical reactions. The Journal of Physical Chemistry 81, 2340-2361. 


\section{For Table of Contents Use Only}



Julius Rentergent, Max D. Driscoll, Sam Hay

Time course analysis of enzyme-catalyzed DNA polymerization 